\title{
Alkali Fusion Synthesis of Zeolitic Materials from Waste Dehydrated Cake Discharged from Recycling of Construction Waste Soil
}

\author{
Takaaki Wajima \\ Department of Urban Environment Systems, Chiba University, Chiba, Japan \\ Email:wajima@tu.chiba-u.ac.jp
}

How to cite this paper: Wajima, T. (2017) Alkali Fusion Synthesis of Zeolitic Materials from Waste Dehydrated Cake Discharged from Recycling of Construction Waste Soil. Natural Resources, 8, 300-305. https://doi.org/10.4236/nr.2017.84018

Received: March 28, 2017

Accepted: April 27, 2017

Published: April 30, 2017

Copyright $\odot 2017$ by author and Scientific Research Publishing Inc. This work is licensed under the Creative Commons Attribution-NonCommercial International License (CC BY-NC 4.0). http://creativecommons.org/licenses/by-nc/4.0/

\section{(c) (i) \& Open Access}

\begin{abstract}
An inorganic cation exchanger, zeolitic material, was synthesized from dehydrated cake, which was discharged from recycling of construction waste soil, using the alkali fusion method. The waste clay was mixed with $\mathrm{NaOH}$ powder (the weight ratio of $\mathrm{NaOH} /$ waste clay $=1.0$ ) and then heated at $300^{\circ} \mathrm{C}$ for $1 \mathrm{~h}$ to make a fused material. This fused material was then added to distilled water, and then heated at $90^{\circ} \mathrm{C}, 120^{\circ} \mathrm{C}, 150^{\circ} \mathrm{C}$ and $180^{\circ} \mathrm{C}$ for $12 \mathrm{~h}$ in reaction bombs under autogenous pressure in order to synthesize the cation exchanger. As a result, waste cake can be converted into fused material with high solubility, and zeolitic materials can be synthesized from the fused material. A mixture of zeolite- $\mathrm{X}$ and hydroxysodalite was synthesized at $90^{\circ} \mathrm{C}$ and $120^{\circ} \mathrm{C}$, hydroxysodalite alone was synthesized at $150^{\circ} \mathrm{C}$ and $180^{\circ} \mathrm{C}$. By increasing the synthesis temperature, the cation exchange capacity (CEC) of the product decreased, and the highest $\mathrm{CEC}$ of the product at $90^{\circ} \mathrm{C}$, including zeolite- $\mathrm{X}$, was $2.06 \mathrm{mmol} / \mathrm{g}$, which is $64.3 \%$ of commercial zeolite- $13 \mathrm{X}(3.2 \mathrm{mmol} / \mathrm{g})$.
\end{abstract}

\section{Keywords}

Waste Clay, Alkali Fusion, Zeolite-X, Hydroxysodalite,

Cation Exchange Capacity

\section{Introduction}

The construction industry is an important economic sector that has a large environmental impact in terms of natural resources extraction, energy consumption, pollutants release, greenhouse gases emissions and amount of waste generated. Hence, promoting and practicing sustainability in construction can help preserve the planet's ecosystems, conserve natural resources and improve the environmental conditions of all living organisms on earth. Recycling and reuse 
of construction and demolition wastes (CDW) is one such attempt to achieve this goal.

Construction waste soil is one of the CDW, and desired to be recycled. Construction waste soil was sorted into three materials, crushed stone, sand and dehydrated cake, in the recycle plant. Recently, crushed stone and sand are major materials of construction to be sufficient demand. However, dehydrated cake has insufficient demand for construction and other industries, and new utilization using this cake is desired.

In a previous study, we converted waste sandstone cake, which was discharged from one of the quarry in Japan, into a zeolitic material by the alkali fusion method and succeeded in synthesizing crystalline zeolite-13X with a high cation exchange capacity (CEC) [1] [2] [3]. By alkali fusion, most of the crystalline phases could be converted into soluble phases and transformed into zeolite crystals. This is a new way of converting the inorganic waste into functional materials.

In this study, we attempted to convert waste dehydrated cake discharged from construction waste soil into inorganic materials with CEC using alkali fusion. The crystalline phases in the cake were converted into the fused material with soluble phases by alkali fusion, and were then used to synthesize an inorganic cation exchanger, zeolitic material.

\section{Materials and Methods}

\subsection{Waste Cake}

The waste cake was obtained from one of the companies in Akita Prefecture, Japan. Before the experiment, the waste cake was crushed and sieved under 500 $\mu \mathrm{m}$, and then dried in an oven at $60^{\circ} \mathrm{C}$ overnight.

The chemical compositions of the waste cake determined by X-ray fluorescent spectrometry (XRF) (ZSX101e, Rigaku) are listed in Table 1. The waste cake was mainly composed of $\mathrm{SiO}_{2}$ and $\mathrm{Al}_{2} \mathrm{O}_{3}$, and some minor contents.

\subsection{Zeolite Synthesis}

The experimental procedure is shown in Figure 1. First, $10 \mathrm{~g}$ of waste cake was mixed with $10 \mathrm{~g}$ of $\mathrm{NaOH}$ and ground to obtain a homogeneous mixture. This

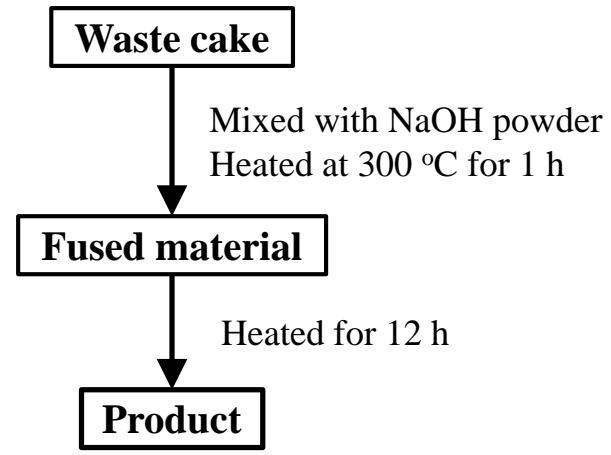

Figure 1. Experimental procedure of this experiment. 
Table 1. Chemical composition of waste cake..

\begin{tabular}{ccccccccccc}
\hline & $\mathrm{SiO}_{2}$ & $\mathrm{Al}_{2} \mathrm{O}_{3}$ & $\mathrm{Na}_{2} \mathrm{O}$ & $\mathrm{K}_{2} \mathrm{O}$ & $\mathrm{MgO}$ & $\mathrm{CaO}$ & $\mathrm{Fe}_{2} \mathrm{O}_{3}$ & $\mathrm{SO}_{3}$ & $\mathrm{P}_{2} \mathrm{O}_{5}$ & $\mathrm{TiO}_{2}$ \\
\hline Oxide (wt.\%) & 57.1 & 22.1 & 1.8 & 1.9 & 2.7 & 3.6 & 8.7 & 0.5 & 0.4 & 0.9 \\
\hline
\end{tabular}

mixture was then heated in a nickel crucible, which is stable for alkali fusion in this experiment, in air at $300^{\circ} \mathrm{C}$ for $1 \mathrm{~h}$. The resultant fused mixture was cooled to room temperature and ground again. To determine the solubility of Si and $\mathrm{Al}$ in raw cake and fused material, $0.1 \mathrm{~g}$ of the solid was added into $10 \mathrm{~mL}$ of $1 \mathrm{M}$ $\mathrm{HCl}$ solution, and shaken for $6 \mathrm{~h}$. This mixture was filtered, and the concentrations of $\mathrm{Si}$ and $\mathrm{Al}$ in the filtrate were determined by atomic absorption spectrometer (AAS) (AAna list 200, Perkin Elmer Japan) to calculate the solubility of the solid $(\mathrm{mg} / \mathrm{g})$. Next, $2 \mathrm{~g}$ of the mixture was added to $10 \mathrm{~mL}$ of distilled water in reaction bombs and heated at $90^{\circ} \mathrm{C}, 120^{\circ} \mathrm{C}, 150^{\circ} \mathrm{C}$ and $160^{\circ} \mathrm{C}$ for $12 \mathrm{~h}$ in an electric oven under autogenous pressure. After heating, the solid product was filtered, washed with distilled water, and dried in a drying oven at $60^{\circ} \mathrm{C}$ overnight. The phases of the product were analyzed by X-ray diffraction spectroscopy (XRD) (XRD-DSC-XII, Rigaku) and the CEC of the product was measured by the modified Schörrenberg's method [4] as follows. The exchangeable cations in the product were replaced by $\mathrm{NH}_{4}^{+}$using $1 \mathrm{M}$ ammonium acetate solution. This process was repeated three times at $20 \mathrm{~min}$ per exchange. The sample was then washed with $80 \%$ EtOH solution to remove excess salt. The $\mathrm{NH}_{4}^{+}$was then replaced by $\mathrm{K}^{+}$using $10 \% \mathrm{KCl}$ solution for $20 \mathrm{~min}$. This process was also repeated three times. Finally, the $\mathrm{NH}_{4}^{+}$in the $\mathrm{KCl}$ solution was analyzed by the method described by Koyama et al. [5] to determine the CEC of the sample.

\section{Results and Discussion}

Figure 2 shows the XRD patterns obtained for (a) raw cake and (b) fused material. The raw cake comprised silicate and aluminosilicate minerals, such as quartz, albite and clinochlore (Figure 2(a)). After fusion, most of the phases in the raw cake were initially converted into soluble sodium silicate and sodium silicate hydrate (Figure 2(b)).

Table 2 shows the solubilities of $\mathrm{Si}$ and $\mathrm{Al}$ from raw waste cake and fused material. The solubility of raw cake is low, Si: $4.45 \mathrm{mg} / \mathrm{g}$ and Al: $5.77 \mathrm{mg} / \mathrm{g}$. After alkali fusion of waste cake, the solubilities of $\mathrm{Si}$ and $\mathrm{Al}$ from fused material are $74.1 \mathrm{mg} / \mathrm{g}$ and $26.51 \mathrm{mg} / \mathrm{g}$, respectively, which are higher than those from raw cake.

From these results, waste cake can be converted into the fused material with high solubility, due to the formation of sodium salts, such as sodium silicate, by alkali fusion.

Figure 3 shows the $\mathrm{X}$-ray diffraction patterns of the product synthesized at (a) $90^{\circ} \mathrm{C}$, (b) $120^{\circ} \mathrm{C}$, (c) $150^{\circ} \mathrm{C}$ and (d) $180^{\circ} \mathrm{C}$. Zeolite-X and hydroxysodalite were synthesized from fused material, anddifferent phases in the product were confirmed at each reaction temperature. The mixture of zeolite- $\mathrm{X}$ and hydroxysodalite was synthesized at $90^{\circ} \mathrm{C}$ and $120^{\circ} \mathrm{C}$, and hydroxysodalite alone was 


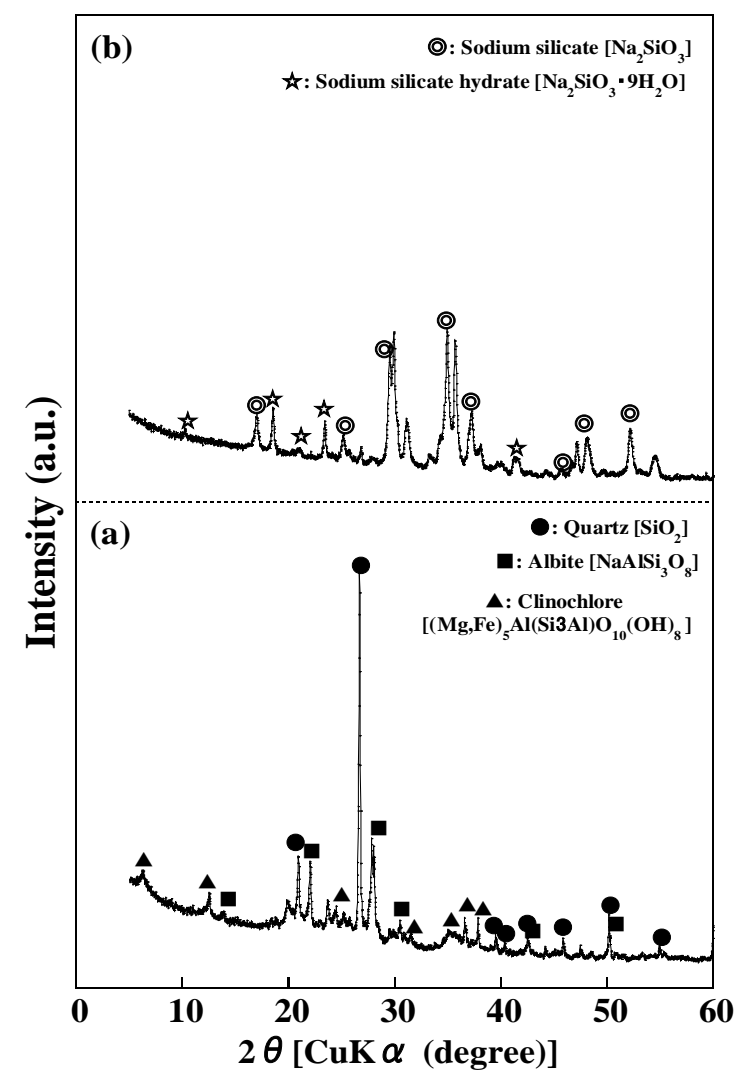

Figure 2. XRD patterns of (a) raw waste cake and (b) fused material.

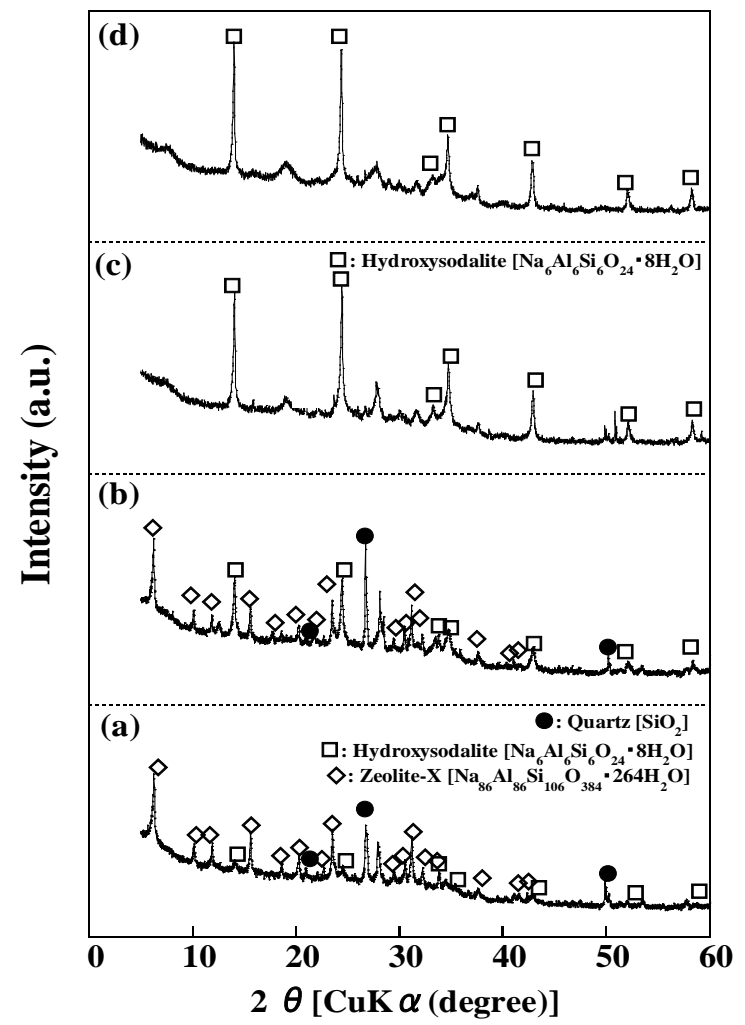

Figure 3. XRD patterns of the products synthesized at (a) $90^{\circ} \mathrm{C}$; (b) $120^{\circ} \mathrm{C}$; (c) $150^{\circ} \mathrm{C}$ and (d) $180^{\circ} \mathrm{C}$. 
synthesized at $150^{\circ} \mathrm{C}$ and $180^{\circ} \mathrm{C}$. It was confirmed that quartz including the raw cake was present inthe products obtained at $90^{\circ} \mathrm{C}$ and $120^{\circ} \mathrm{C}$, and diminished in the product at $150^{\circ} \mathrm{C}$ and $180^{\circ} \mathrm{C}$. This means that a part of the mineral phases in the cake, quartz, remained after alkali fusion due to the insufficient fusion condition, and all mineral phases in the cake can be converted into the zeolite phases at $150^{\circ} \mathrm{C}$ and $180^{\circ} \mathrm{C}$ through alkali fusion treatment.

Figure 4 shows the SEM photographs of (a) raw cake (b) fused material, and the products synthesized at(c) $90^{\circ} \mathrm{C}$ and (d) $180^{\circ} \mathrm{C}$. Different morphologies of each sample were observed. The raw cake was an aggregate of some minerals (Figure 4(a)), while fused material was a large particle with a melting surface resulting from the formation of sodium salts by alkali fusion (Figure 4(b)). In the product synthesized at $90^{\circ} \mathrm{C}$, octahedral crystals of zeolite-X, can be observed in the product, as shown in Figure 4(c), while in the product synthesized at $180^{\circ} \mathrm{C}$, ball-like aggregate of hydroxysodalite can be observed (Figure $4(\mathrm{~d})$ ).

Table 3 shows the cation exchange capacities of raw waste cake, fused material, and the product synthesized at $90^{\circ} \mathrm{C}-180^{\circ} \mathrm{C}$. The $\mathrm{CEC}$ of the product decreased with the increase in heating temperature. Hydroxysodalite has a lower CEC than zeolite-X and is easily synthesized due to the increase of heating temperature. The product with the highest CEC was synthesized at $90^{\circ} \mathrm{C}$, and the CEC was $2.06 \mathrm{mmol} / \mathrm{g}$. It is noted that the CEC of commercial zeolite-13X (Wako) is $3.2 \mathrm{mmol} / \mathrm{g}$, which is 1.55 times greater than that of the obtained product.

\section{Conclusion}

An inorganic cation exchanger can be synthesized from waste cake using the alkali fusion method. Waste cake can be converted into the fused material with
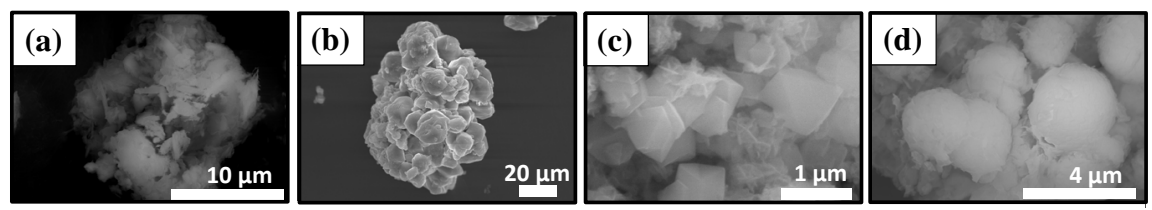

Figure 4. SEM photos of (a) raw cake; (b) fused material, and the products synthesized at (c) $90^{\circ} \mathrm{C}$ and (d) $180^{\circ} \mathrm{C}$.

Table 2. Solubilities of Si and $\mathrm{Al}$ from raw waste cake and fused material.

\begin{tabular}{ccccc}
\hline & \multicolumn{2}{c}{ Raw waste cake } & \multicolumn{2}{c}{ Fused material } \\
\cline { 2 - 5 } & $\mathrm{Si}$ & $\mathrm{Al}$ & $\mathrm{Si}$ & $\mathrm{Al}$ \\
\hline Solubility $(\mathrm{mgl} / \mathrm{g})$ & 4.45 & 5.77 & 74.10 & 26.51 \\
\hline
\end{tabular}

Table 3. CECs of raw waste cake, fused material, and the products.

\begin{tabular}{lcccccc}
\hline & \multirow{2}{*}{ Raw waste cake } & Fused material & \multicolumn{4}{c}{ The product } \\
\cline { 4 - 7 } & & & $90^{\circ} \mathrm{C}$ & $120^{\circ} \mathrm{C}$ & $150^{\circ} \mathrm{C}$ & $180^{\circ} \mathrm{C}$ \\
\hline $\mathrm{CEC}(\mathrm{mmol} / \mathrm{g})$ & 0.17 & 1.16 & 2.06 & 2.04 & 1.84 & 1.14 \\
\hline
\end{tabular}


high solubility by alkali fusion, and zeolite- $\mathrm{X}$ and hydroxysodalite were synthesized. The mixture of zeolite- $\mathrm{X}$ and hydroxysodalite was synthesized at $90^{\circ} \mathrm{C}$ and $120^{\circ} \mathrm{C}$, and hydroxysodalite alone was synthesized at $150^{\circ} \mathrm{C}$ and $180^{\circ} \mathrm{C}$. The CEC of the product decreased with an increase in heating temperature, because hydroxysodalite has a lower CEC than zeolite-X and is easily synthesized due to the increase of heating temperature. The product with the highest CEC (2.06 $\mathrm{mmol} / \mathrm{g}$ ) was the product synthesized at $90^{\circ} \mathrm{C}$, which is $64.3 \%$ of CEC of commercial zeolite-13X.

\section{Acknowledgements}

This work was supported by the Japan Crushed Stone Association Foundation, for which we would like to express our gratitude.

\section{References}

[1] Wajima, T., Yoshizuka, K., Hirai, T. and Ikegami, Y. (2008) Synthesis of Zeolite X from Waste Sandstone Cake Using Alkali fusion Method. Materials Transactions, 49, 612-618. https://doi.org/10.2320/matertrans.MRA2007250

[2] Wajima, T., Munakata, K. and Ikegami, Y. (2010) Conversion of Waste Sandstone Cake into Crystalline Zeolite X Using Alkali Fusion. Materials Transactions, 51, 849-854. https://doi.org/10.2320/matertrans.MH200905

[3] Wajima, T. and Munakata, K. (2012) Material Conversion from Waste Sandstone Cake into Cation Exchanger Using Alkali Fusion. Ceramics International, 38, 17411744. https://doi.org/10.1016/j.ceramint.2011.09.028

[4] Development of New Utilization of Materials, Natural Zeolite and Its Utilization (1994) No. 111 Committee, Japan Society for the Production of Science, Tokyo, 318-325.

[5] Koyama, M., Hori, T. and Kitayama, Y. (1976) IARC Report, Kyoto University, Vol. 2, 11-14.

Submit or recommend next manuscript to SCIRP and we will provide best service for you:

Accepting pre-submission inquiries through Email, Facebook, LinkedIn, Twitter, etc. A wide selection of journals (inclusive of 9 subjects, more than 200 journals)

Providing 24-hour high-quality service

User-friendly online submission system

Fair and swift peer-review system

Efficient typesetting and proofreading procedure

Display of the result of downloads and visits, as well as the number of cited articles

Maximum dissemination of your research work

Submit your manuscript at: http://papersubmission.scirp.org/

Or contact nr@scirp.org 